\title{
Sigma-2 ligands induce tumour cell death by multiple signalling pathways
}

\section{Zeng', J Rothfuss', J Zhang', W Chu', s Vangveravong', Z Tu', F Pan', KC Chang', R Hotchkiss² and RH Mach ${ }^{*, 1,3,4}$}

'Department of Radiology, Division of Radiological Sciences, Washington University School of Medicine, 5 I 0 S Kingshighway Boulevard, St Louis, MO 631 I0, USA; 2Department of Anesthesiology, Washington University School of Medicine, 5 I 0 S Kingshighway Boulevard, St Louis, MO 63I I0, USA; ${ }^{3}$ Department of Cell Biology and Physiology, Washington University School of Medicine, 510 S Kingshighway Boulevard, St Louis, MO 63I I0, USA;

${ }^{4}$ Department of Biochemistry and Molecular Biophysics, Washington University School of Medicine, 510 S Kingshighway Boulevard, St Louis, MO 63I I0, USA

BACKGROUND: The sigma-2 receptor has been identified as a biomarker of proliferating cells in solid tumours. In the present study, we studied the mechanisms of sigma-2 ligand-induced cell death in the mouse breast cancer cell line EMT-6 and the human melanoma cell line MDA-MB-435.

METHODS: EMT-6 and MDA-MB-435 cells were treated with sigma-2 ligands. The modulation of multiple signaling pathways of cell death was evaluated.

RESULTS: Three sigma-2 ligands (WC-26, SVII9 and RHM-138) induced DNA fragmentation, caspase-3 activation and PARP-I cleavage. The caspase inhibitor Z-VAD-FMK partially blocked DNA fragmentation and cytotoxicity caused by these compounds. These data suggest that sigma-2 ligand-induced apoptosis and caspase activation are partially responsible for the cell death. WC-26 and siramesine induced formation of vacuoles in the cells. WC-26, SVI 19, RHM-I38 and siramesine increased the synthesis and processing of microtubule-associated protein light chain 3, an autophagosome marker, and decreased the expression levels of the downstream effectors of mammalian target of rapamycin (mTOR), P70S6K and 4EBPI, suggesting that sigma-2 ligands induce autophagy, probably by inhibition of the mTOR pathway. All four sigma-2 ligands decreased the expression of cyclin DI in a timedependent manner. In addition, WC-26 and SVI 19 mainly decreased cyclin BI, E2 and phosphorylation of retinoblastoma protein (pRb); RHM- 138 mainly decreased cyclin E2; and $10 \mu \mathrm{M}$ siramesine mainly decreased cyclin BI and pRb. These data suggest that sigma-2 ligands also impair cell-cycle progression in multiple phases of the cell cycle.

CONCLUSION: Sigma-2 ligands induce cell death by multiple signalling pathways.

British Journal of Cancer (2012) 106, 693-701. doi:I0.1038/bjc.2011.602 www.bjcancer.com

Published online 17 January 2012

(c) 2012 Cancer Research UK

Keywords: sigma-2 receptors; apoptosis; autophagy; cell cycle; breast tumour cells

Sigma receptors are a distinct class of receptors that are found in many tumours and normal tissues. Sigma receptors have been associated with many cellular and organ processes, including motor function, endocrine function, proliferation, immunoregulation and ion channel modulation (Walker et al, 1990; Hellewell et al, 1994; Megalizzi et al, 2010). Radioligand binding studies and biochemical analyses have shown that there are at least two types of sigma receptors, sigma-1 $(\sim 25 \mathrm{kDa})$ and sigma-2 $(\sim 21.5 \mathrm{kDa})$. The sigma-1 receptor has been cloned from many species (Hanner et al, 1996; Seth et al, 1997). Recently the progesterone receptor membrane component 1 (PGRMC1) protein complex was identified as the putative sigma-2 receptor-binding site (Xu et al, 2011). Sigma-2 receptors are expressed in high density in nearly all human and rodent tumour cell lines (Vilner et al, 1995). Sigma-2 receptor densities have been correlated with the grade of some human and bovine tumours (Bem et al, 1991; Colabufo et al, 2006; Roperto et al, 2010). The density of sigma-2 receptors in proli-

*Correspondence: Dr RH Mach; E-mail: rhmach@mir.wustl.edu Revised 27 October 2011; accepted 19 December 2011; published online 17 January 2012 ferating mouse mammary adenocarcinoma cells was found to be $\sim 10$-fold higher than that in the corresponding quiescent tumour cells both in vitro and in vivo (Mach et al, 1997; Wheeler et al, 2000). These observations have led to the development of the sigma-2 ligands as molecular probes for diagnostic imaging of solid tumours (Wheeler et al, 2000; Mach et al, 2001a; Kawamura et al, 2003), and the identification of sigma-2 receptors as a potential target for treatment of cancer (John et al, 1998; Caveliers et al, 2001).

Apoptosis (programmed cell death) is a physiological process that is important for development, homeostasis and suppression of oncogenesis (Jacobson et al, 1997). Deregulated apoptosis has been implicated in many diseases, including ischemic stroke and cancer (Reed, 2002). It is well known that the caspase family has a central role in both the intrinsic and extrinsic pathways of apoptosis. Caspase-3, the 'executioner' caspase, is a key enzyme, which degrades proteins such as gelsolin and lamin, leading to apoptotic cell death (Reed, 2002). Sigma-2 ligands with different chemical structures have been reported to induce apoptosis in several tumour cell lines (Brent et al, 1996; Crawford and Bowen, 2002; Crawford et al, 2002, 2003; Barbieri et al, 2003; Ostenfeld et al, 2005; Cassano et al, 2009). Although two of these studies (Crawford and Bowen, 2002; Ostenfeld et al, 2005) have shown that prolonged exposure to 
sigma-2 ligands kills cancer cells by a caspase-independent apoptotic pathway, a complete understanding of how sigma-2-selective ligands induce cell death has not yet been established.

Autophagy is a lysosomal degradation pathway for cytoplasmic materials (Glick et al, 2010). At basal levels, autophagy maintains cellular homeostasis by removing misfolded or aggregated proteins, and by clearing damaged cellular organelles. Autophagy is strongly induced upon nutrient deprivation and enhances cell survival by degrading nonessential components of the cell to generate nutrients for vital biological processes. Autophagy begins with an isolation membrane, also known as a phagophore. The phagophore then expands to engulf cytoplasmic materials, forming a closed double-membrane autophagosome. Autophagosomes fuse with endosomal and/or lysosomal vesicles, promoting degradation of autophagosomal contents by lysosomal acid proteases. The degradation products can be re-used for cellular metabolism. By contrast, excessive autophagy can result in non-apoptotic cell death (Platini et al, 2010). Mammalian target of rapamycin (mTOR) promotes cell growth and inhibits autophagy (Janku et al, 2011). Mammalian target of rapamycin kinase forms two distinct multiprotein complexes called mTORC1 and mTORC2. Mammalian target of rapamycin-C1 activity results in phosphorylation of S6 ribosomal protein kinase (S6K), phosphorylation of eukaryotic initiation factor 4E-binding protein (4EBP1) and subsequent activation of the protein translational machinery in the cell. Mammalian target of rapamycin-C2 mediates Akt activation, which in turn stimulates and activates mTORC1. Because of its dual role in cell survival and cell death, both inhibition and activation of the autophagic lysosomal pathway are novel strategies for treating cancer (Platini et al, 2010). In fact, Ostenfeld et al (2008) have proposed combination therapy of siramesine, a sigma-2 ligand, with drugs that inhibit autophagy as a strategy for treating cancer.

The cell cycle can be described by four successive cellular phases: a phase of cell growth to prepare for DNA replication $\left(G_{1}\right)$, a phase of DNA synthesis and replication (S), and a phase of cell growth and active synthesis of factors $\left(\mathrm{G}_{2}\right)$ required for mitosis $(\mathrm{M})$ (Malumbres and Barbacid, 2009). Progression through the cell cycle is regulated by sequential waves of different cyclin/cyclin-dependent kinase (CDK) activities. Cyclins are synthesised and destroyed at specific time points during the cell cycle, thus regulating CDK kinase activities in a timely manner. Cyclin-dependent kinase-cyclin complexes directly involved in cell-cycle control include three interphase CDKs (CDK2, CDK4 and CDK6), a mitotic CDK (CDK1) and four classes of cyclins (cyclins A, $\mathrm{B}, \mathrm{D}$ and $\mathrm{E})$. Mitogenic signals first induced the expression of D-type cyclins (D1, D2 and D3). The D-type cyclins bind to and activate CDK4 and $\mathrm{CDK} 6$ during $\mathrm{G}_{1}$ phase, leading to phosphorylation of the retinoblastoma protein $(\mathrm{Rb})$. Phosphorylation of $\mathrm{Rb}$ releases the $\mathrm{E} 2 \mathrm{~F}$ transcription factors, which can then activate genes essential for $G_{1}-S$ transition and S-phase, including E-type cyclins (Witzel et al, 2010). The E-type cyclins are required to activate Cdk2 for proper completion of the $G_{1}$ phase, as well as for initiating DNA replication. Once cells enter S-phase, Cdk2-cyclin E complexes need to be silenced to avoid re-replication of DNA. The A-type cyclins accumulate during S-phase. Cyclin-dependent kinase-2 - cyclin A complexes have been reported to phosphorylate numerous proteins that are required for proper completion and exit from S-phase. During $\mathrm{G}_{2}$, the A-type cyclins are degraded by ubiquitin-mediated proteolysis whereas the B-type cyclins are actively synthesised. As a consequence, Cdk1 binds to the B-type cyclins - an association believed to regulate several events during both the $\mathrm{G}_{2}-\mathrm{M}$ transition and progression through mitosis. Finally, inactivation of Cdk1-cyclin B complexes is required for proper exit from mitosis. This inactivation is accomplished by degradation of the B-type cyclins through the proteolytic pathway mediated by ubiquitination. Cell-cycle malfunction may cause cell death (Allan and Clarke, 2008; Clarke and Allan, 2009). Recent results indicate that regulation of apoptosis is directly linked with cell-cycle checkpoints by common components (Clarke and Allan, 2009).
Few studies have investigated the effects of sigma-2 ligands on the cell cycle.

Our group has previously reported the synthesis and in vitro characterisation of a number of structurally diverse ligands with a high affinity for sigma-2 receptors (Mach et al, 2001b, 2003, 2004). By screening these sigma ligands for their cytotoxicity, we identified three potent sigma-2-selective ligands, WC-26, SV119 and RHM-138, that killed mouse breast cancer EMT-6 and human MDA-MB-435 melanoma tumour cells with $\mathrm{EC}_{50} \mathrm{~s}$ in micromolar range after a 48-h exposure. The aim of the present study was to explore the mechanism by which these three sigma-2-selective ligands induce cell death. The data presented in this report indicate that treatment of EMT- 6 and MDA-MB- 435 cancer cells with these sigma-2 ligands induces multiple mechanisms of cell death, including apoptosis, autophagy and cell-cycle impairment.

\section{MATERIALS AND METHODS}

\section{Cell culture conditions}

EMT-6 mouse breast cancer cells were grown in DMEM containing $10 \%$ fetal bovine serum, $100 \mathrm{U} \mathrm{ml}^{-1}$ penicillin and $100 \mu \mathrm{g} \mathrm{ml}^{-1}$ streptomycin. MDA-MB-435 human melanoma cells were grown in MEM containing $10 \%$ fetal bovine serum, $2 \mathrm{~mm} \mathrm{~L}$-glutamine, $1 \mathrm{mM}$ sodium pyruvate, $1 \%$ nonessential amino acids (Mediatech Inc., Manassas, VA, USA), 2\% MEM vitamins (Invitrogen, Carlsbad, CA, USA), $100 \mathrm{U} \mathrm{ml}^{-1}$ penicillin and $100 \mu \mathrm{g} \mathrm{ml}^{-1}$ streptomycin. Both cell lines were maintained at $37{ }^{\circ} \mathrm{C}$ in a humidified incubator under a $5 \% \mathrm{CO}_{2} / 95 \%$ air atmosphere.

\section{MTS assay}

The cytotoxicity of sigma-2 ligands was determined using the CellTiter96 Aqueous One Solution (Promega, Madison, WI, USA), which contains a tetrazolium compound (3-(4,5-dimethylthiazol2-yl)-5-(3-carboxymethoxyphenyl)-2-(4-sulphophenyl)-2H-tetrazo lium, inner salt; MTS).

\section{LDH assay}

Lactate dehydrogenase (LDH) release assay was performed using the Cytotox 96 Non-Radioactive Cytotoxicity Assay (Promega) according to the manufacturer's protocol.

\section{Detection of intracellular caspase-3 activity}

Activation of endogenous caspase- 3 by sigma ligands was measured using the CellProbe HT caspase- 3 whole-cell assay (Beckman Coulter, Fullerton, CA, USA) (see Supplementary Information for description of caspase-3 assay).

\section{Flow cytometry}

Flow cytometric analysis was performed using a FACScan (Becton Dickinson, Fullerton, CA, USA) equipped with an air-cooled argon laser. TUNEL (terminal deoxynucleotidyl transferase dUTP nick-end labelling)-positive cells were detected with FITC-dUTP and quantified by flow cytometry using a TUNEL assay according to the manufacturer's protocol (Apo-direct Kit; BD Biosciences Pharmingen, San Diego, CA, USA). Briefly, the cells were detached from the culture dishes with trypsin, washed with phosphate-buffered saline (PBS) and then fixed in 1\% paraformaldehyde. After washing with PBS twice, the cells were incubated with a DNA labelling solution containing terminal deoxynucleotidyl transferase and FITC-dUTP at $37^{\circ} \mathrm{C}$ for $1 \mathrm{~h}$. After washing with PBS, 7-amino-actinomycin D (7-AAD; BD Biosciences Pharmingen) was added to the cells to stain the nucleic acid at a concentration of $5 \mu \mathrm{l}(0.25 \mu \mathrm{g}) 7-\mathrm{AAD} /$ test $\left(1 \times 10^{6}\right.$ cells $)$. The cells were then analysed by flow cytometry. 
Fluorescein isothiocyanate was excited at $488 \mathrm{~nm}$ and emission was collected with a 570 -nm filter. 7-Amino-actinomycin D was excited at $488 \mathrm{~nm}$ and emission was collected using a 650-nm long-pass filter.

\section{Western blot analysis}

EMT- 6 cells $\left(2 \times 10^{5}\right)$ or MDA-MB- 435 cells $\left(4 \times 10^{5}\right)$ were plated in $100-\mathrm{mm}$ culture dishes $24 \mathrm{~h}$ prior to treatment with the sigma-2selective ligands. For detection of caspase- 3 activation, the cells were treated with WC-26 $(40 \mu \mathrm{M}$ for EMT-6, $80 \mu \mathrm{M}$ for MDA-MB-435), SV119 $(100 \mu \mathrm{M})$ or RHM-138 $(40 \mu \mathrm{M})$. For detection of autophagy and cell-cycle impairment, MDA-MB-435 cells were treated with WC-26 $(100 \mu \mathrm{M})$, SV119 $(100 \mu \mathrm{M})$, RHM-138 $(40 \mu \mathrm{M})$ or siramesine $(10 \mu \mathrm{M})$. At various time points, cells were harvested and cell lysates were prepared using CHAPS buffer (50 mM Pipes/ $\mathrm{HCl}$ (pH 6.5), 2 mM EDTA, 0.1\% CHAPS (3-[(3-cholamidopropyl)dimethylammonio]-1-propane sulphonate), $20 \mu \mathrm{g} \mathrm{ml}^{-1}$ leupeptin, $10 \mu \mathrm{g} \mathrm{ml}^{-1}$ pepstatin A and $10 \mu \mathrm{g} \mathrm{ml}^{-1}$ aprotinin). Aliquots of protein $(30 \mu \mathrm{g})$ from each sample were analysed using standard immunoblotting procedures. Rabbit antibodies of caspase-3, PARP-1, LC3B, cyclin B1, cyclin D1, cyclin E2, pRb (Ser780), phospho-p70S6K (Thr389) and phospho-4EBP1 (Thr37/46), and a mouse antibody of cyclin A were purchased from Cell Signaling Technology (Danvers, MA, USA). All primary antibodies were used at a $1: 1000$ dilution. The secondary antibody was horseradish peroxidase (HRP)-conjugated goat anti-rabbit IgG or HRP-conjugated horse anti-mouse IgG (Cell Signaling Technology) at a 1:3000 or $1: 10000$ dilution, respectively. The SuperSignal WestDura Extended Duration Substrate assay kit (Pierce Biotechnology Inc., Rockford, IL, USA) was used to detect the secondary antibody. For stripping western blots, the blot was incubated with stripping buffer (Pierce Biotechnology Inc.) for $15 \mathrm{~min}$ at room temperature.

\section{Transmission electron microscopy}

MDA-MB-435 cells were plated in a $35-\mathrm{mm}$ cell culture dish at a cell density of $3.2 \times 10^{5}$ cells per dish for $24 \mathrm{~h}$. The cells were then treated with $100 \mu \mathrm{M} \mathrm{WC}-26$ or $10 \mu \mathrm{m}$ siramesine for $0,4,8$ and $16 \mathrm{~h}$. The cells were quickly rinsed with PBS twice at room temperature and then fixed with $1 \mathrm{ml}$ of $2.5 \%$ glutaraldehyde in $0.01 \mathrm{M} \mathrm{Na}$ cacodylate buffer at $4{ }^{\circ} \mathrm{C}$ until use. After rinsing with PBS, fixed cells were sequentially stained with osmium tetroxide and uranyl acetate, and then dehydrated and embedded in overturned gelatin capsules containing Polybed 812 resin (Polysciences, Warrington, PA, USA). The resin blocks were thin sectioned at $90-100 \mathrm{~nm}$ on a Reichert-Jung Ultracut microtome, post-stained in uranyl acetate and lead citrate, viewed on a Zeiss 902 Electron Microscope, and recorded with Kodak EM film.

\section{Statistical analysis}

The results are expressed as the mean \pm s.d. based on three independent experiments performed in triplicate. Differences among groups were statistically analysed by two-tailed Student's $t$-test. A $P$-value of $<0.05$ was considered significant.

\section{RESULTS}

\section{Sigma-2 ligands induced cytotoxicity}

The chemical structures of the four sigma-2 ligands are shown in Figure 1A. Using the MTS assay, dose-response curves were generated after exposing EMT-6 and MDA-MB-435 cells to increasing concentrations of WC-26, SV119, RHM-138 and siramesine for 24 or $48 \mathrm{~h}$. Cell kill increased with increasing dose of and exposure time to the four sigma-2 ligands (Figure 1B). All $\mathrm{EC}_{50}$ s were in the micromolar range (Table 1).

\section{Sigma-2 ligands induced caspase- 3 activation}

To assess if caspase-mediated apoptosis was involved in the cytotoxic pathway, caspase- 3 activity was measured by a whole-cell assay described under Materials and Methods. The EMT-6 cells
A<smiles>COc1ccc([N+](=O)[O-])cc1NC(=O)OC1CC2CCCC(C1)N2Cc1ccc(N(C)C)cc1</smiles><smiles>COc1ccc(OC)c(NC(=O)OC2CC3CCCC(C2)N3CCCCCN)c1</smiles><smiles>O[C@H](CN1C2CCC1CC(c1ccccc1)C2)c1cccc(Br)c1</smiles>

RHM-138

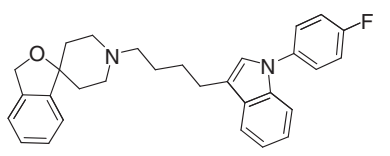

Siramesine
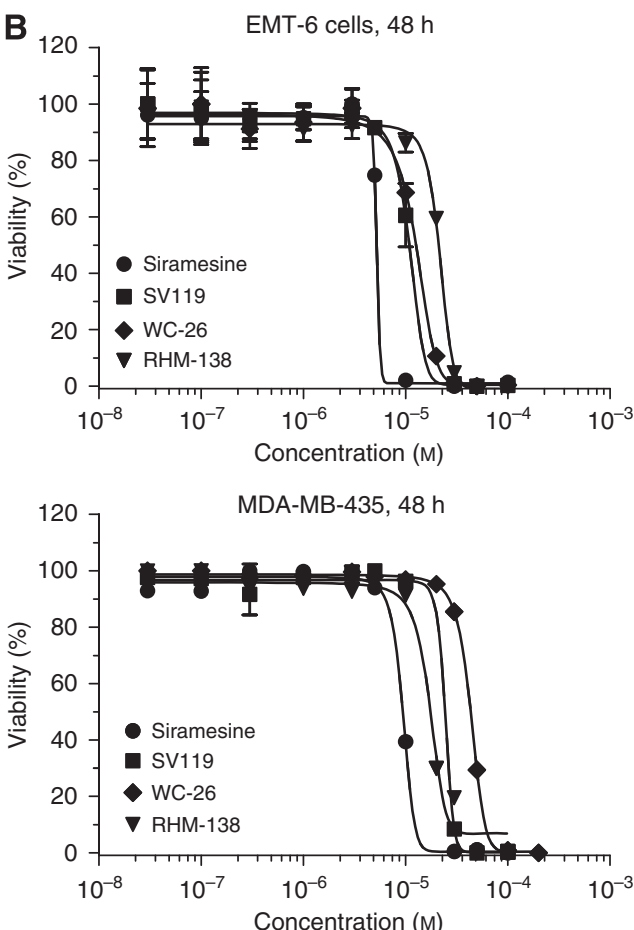

Figure I Sigma-2 ligands decreased viability in EMT-6 and MDA-MB-435 cells. (A) Chemical structures of the sigma-2 ligands. (B) EMT-6 or MDA-MB435 cells were treated with increasing concentrations of the sigma-2 ligands WC-26, SVI I 9, RHM- I 38 and siramesine for 48 h. Cell viability was determined by MTS assay. The bars represent the mean \pm s.e.m. of at least three independent experiments. 
Table I Cytotoxicity of sigma-2 ligands

\begin{tabular}{lcccc}
\hline Compound & $\begin{array}{c}\text { EMT-6 } \\
\text { EC }_{\mathbf{5 0}}(\boldsymbol{\mu} \mathbf{M}, \mathbf{2 4} \mathbf{h})\end{array}$ & $\begin{array}{c}\text { EMT-6 } \\
\text { EC }_{\mathbf{5 0}}(\boldsymbol{\mu} \mathbf{M}, \mathbf{4 8} \mathbf{h})\end{array}$ & $\begin{array}{c}\text { MDA-MB-435 } \\
\text { EC }_{\mathbf{5 0}}(\boldsymbol{\mu} \mathbf{M}, \mathbf{2 4} \mathbf{h})\end{array}$ & $\begin{array}{c}\text { MDA-MB-435 } \\
\mathbf{E C}_{\mathbf{5 0}}(\boldsymbol{\mu} \mathbf{M}, \mathbf{4 8} \mathbf{h})\end{array}$ \\
\hline WC-26 & $42.5 \pm 3.5$ & $12.3 \pm 1.6$ & $49.7 \pm 2.5$ & $42.6 \pm 2.3$ \\
SVII9 & $16.0 \pm 1.4$ & $11.4 \pm 1.7$ & $36.7 \pm 3.33$ & $18.5 \pm 1.9$ \\
RHM-138 & $32.5 \pm 3.5$ & $19.5 \pm 2.0$ & $26.7 \pm 4.25$ & $17.8 \pm 1.6$ \\
Siramesine & & $5.3 \pm 1.0$ & & $9.3 \pm 0.9$ \\
\hline
\end{tabular}

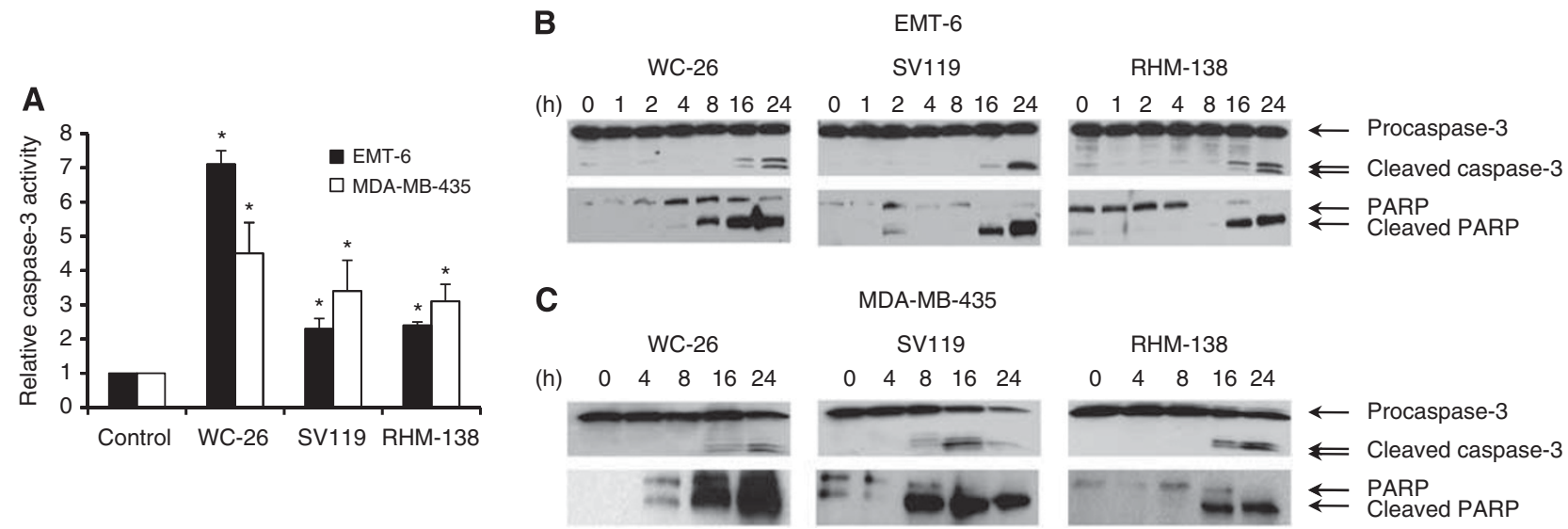

Figure 2 Sigma-2 ligands induced caspase-3 activation. (A) EMT-6 and MDA-MB-435 cells were treated for $24 \mathrm{~h}$ with the sigma-2 ligands at concentrations that resulted in the highest level of caspase-3 activation (40 $\mu \mathrm{M}$ WC-26, $40 \mu \mathrm{M}$ SVI I 9 or $40 \mu \mathrm{M}$ RHM- I 38 for EMT-6 cells; $80 \mu \mathrm{M}$ WC-26, $80 \mu \mathrm{M}$ SVI 19 or $50 \mu \mathrm{M}$ RHM- 138 for MDA-MB-435 cells). Caspase-3 activation was determined by the CellProbe HT caspase-3 whole-cell assay. $* P<0.00$ I compared with untreated control. The bars indicate the mean \pm s.d. of the representative data of at least three independent experiments. (B and $\mathbf{C})$ Sigma- 2 ligands induced procaspase- 3 and PARP-I cleavage as shown by western blot analysis in EMT-6 cells $(\mathbf{B})$ and MDA-MB-435 cells $(\mathbf{C})$. EMT-6 cells were treated for $0-24 \mathrm{~h}$ prior to assay with WC-26 $(40 \mu \mathrm{M})$, SVII9 (I $00 \mu \mathrm{M})$ or RHM-I $38(40 \mu \mathrm{M})$. MDA-MB-435 cells were treated for 0-24h with WC-26 $(80 \mu \mathrm{M})$, SVII9 (I00 $\mu \mathrm{M})$ or RHM-I38 (40 $\mu \mathrm{M})$.

were treated with $40 \mu \mathrm{M}$ WC-26, $40 \mu \mathrm{M}$ SV119 or $40 \mu \mathrm{M}$ RHM-138 for $24 \mathrm{~h}$. The data showed that caspase- 3 activation in treated cells increased by 7-, 2.5- and 2.5-fold, respectively, over activation measured in untreated control cells (Figure 2A). MDA-MB-435 cells were also treated for $24 \mathrm{~h}$ with $80 \mu \mathrm{M}$ WC-26, $80 \mu \mathrm{M} \mathrm{SV} 119$ or $50 \mu \mathrm{M}$ RHM-138, and caspase-3 activities were shown to increase by $4.5-, 3.5$ - and 3-fold, respectively (Figure $2 \mathrm{~A}$ ).

Caspase- 3 activation was also demonstrated by western blot analysis. Activation of caspase- 3 requires proteolytic processing of inactive procaspase-3 $(35 \mathrm{kDa})$ into inactive $19-\mathrm{kDa}$ and active $17-\mathrm{kDa}$, and 12-kDa caspase-3, fragments. EMT-6 (Figure 2B) and MDA-MB- 435 cells (Figure $2 \mathrm{C}$ ) were treated for $0-24 \mathrm{~h}$ prior to the assay. All three sigma-2 ligands induced procaspase- 3 cleavage in both EMT-6 and MDA-MB-435 cells after an 8- to 24-h treatment. Poly(ADP-ribose) polymerase-1 (PARP-1), the 116-kDa poly(ADPribose) polymerase, is one of the main cleavage targets of caspase- 3 in vivo. The western blot analyses demonstrated that all three sigma-2 ligands induced PARP-1 cleavage in both cell lines (Figure $2 \mathrm{~B}$ and $\mathrm{C}$ ). Collectively, these data indicate that our three sigma-2 ligands induced cell death through an apoptotic pathway.

To determine whether caspases are responsible for the sigma-2 ligand-induced apoptosis and cell viability, the broad-spectrum caspase inhibitor, Z-VAD-FMK, was added to the culture medium $1 \mathrm{~h}$ before sigma-2 ligands. The effect of this inhibitor on sigma-2 ligand-induced DNA fragmentation was determined by TUNEL staining. The effect of the inhibitor on cell viability following treatment with sigma-2 ligands was determined by MTS assay and $\mathrm{LDH}$ assay. The results showed that DNA fragmentation induced by each of the three sigma-2 ligands was partially blocked by Z-VAD-FMK $(100 \mu \mathrm{M})$ in EMT-6 cells (Figure 3A). The decreased cell viability by the sigma-2 ligands was partially rescued by
Z-VAD-FMK (Figure 3B and C). These data suggest that caspase activation, to a certain extent, has a role in sigma-2 ligand-induced cell death. It is worth noting that Z-VAD-FMK partially blocked cell death induced by $20 \mu \mathrm{M}$ siramesine but not by $10 \mu \mathrm{M}$ siramesine (Figure 3B), suggesting that the role of caspase in sigma-2 ligand-induced cell death is concentration-dependent.

\section{Sigma-2 ligands induced autophagy}

Excess levels of autophagy may be responsible for cell death (Platini et al, 2010). We therefore examined whether autophagy was involved in sigma-2 ligand-induced cell death. We first used transmission electron microscopy to examine the ultrastructure of MDA-MB-435 cells after treatment with $100 \mu \mathrm{M}$ WC-26 or $10 \mu \mathrm{M}$ siramesine. Compared with control cells (Figure 4A), 4-h treatment with $100 \mu \mathrm{M}$ WC-26, the earliest time point examined, induced mitochondrial swelling (Figure $4 \mathrm{~B}$, structure indicated by 1 ) and multilayer membrane structures (Figure $4 \mathrm{~B}$, structures indicated by 2 and 3). Typical autophagy compartments, which have double membranes and partially degraded cytoplasmic material, were occasionally observed (Figure $4 \mathrm{C}$, structure 1). Siramesine at $10 \mu \mathrm{M}$ also induced autophagy-like vacuoles (Figure 4D). These ultrastructures suggest that autophagy may be induced by sigma-2 ligands. We further used western blot analysis to examine the processing of microtubule-associated protein light chain 3 (LC3), an autophagosome marker. Light chain 3 is expressed in most cell types as a full-length cytosolic protein, which exists in three isoforms (LC3A, LC3B and LC3C) and is proteolytically cleaved upon induction of autophagy, generating LC3-I. The carboxyterminal glycine of LC3-I then conjugates to phosphatidylethanolamine to generate processed LC3-II. Light chain 3-II is found on 
A

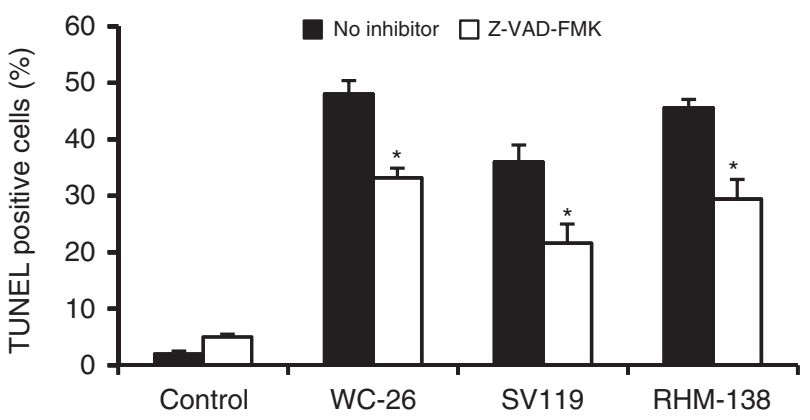

B

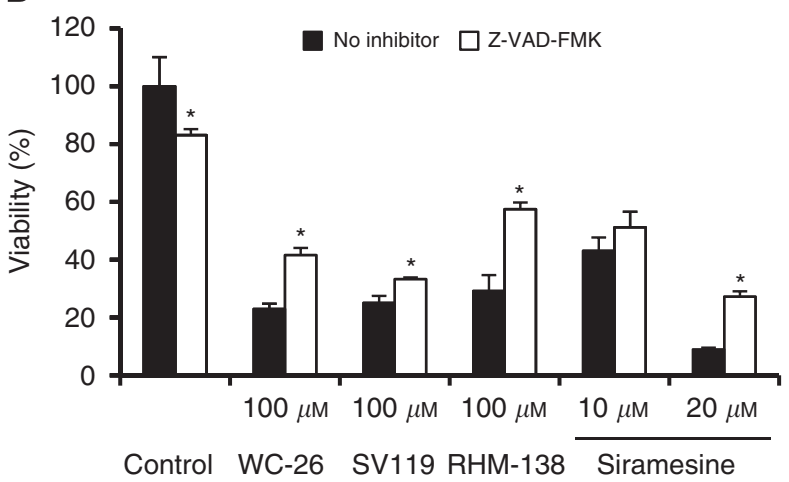

C

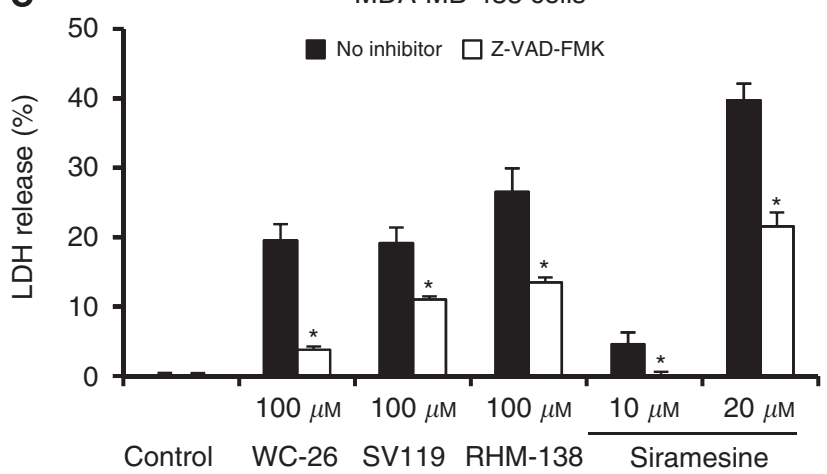

Figure 3 The broad-spectrum caspase inhibitor, Z-VAD-FMK, partially blocked DNA fragmentation, viability and cytotoxicity induced by sigma-2 ligands. (A) EMT-6 cells were pre-treated for I h with Z-VAD-FMK ( $100 \mu \mathrm{M})$, and then treated with WC-26 (40 $\mu \mathrm{M})$ for $48 \mathrm{~h}$, SVII $9(\mathrm{I} 00 \mu \mathrm{M})$ for $16 \mathrm{~h}$ or RHM-I $38(40 \mu \mathrm{M})$ for $16 \mathrm{~h}$. The percentage of TUNEL-positive cells was analysed by flow cytometry $(* P \leqslant 0.00$ I compared with the no inhibitor control). (B and $\mathbf{C}$ ) MDA-MB-435 cells were pre-treated for I h with Z-VAD-FMK $(100 \mu \mathrm{M})$, and then treated with WC-26 $(100 \mu \mathrm{M})$,

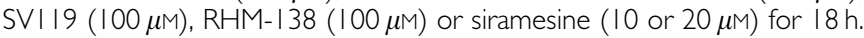
Viability of the cells was measured by MTS assay $(\mathbf{B})$. Cytotoxicity to the cells was measured by LDH assay. ( $P<0.05$ compared with the no inhibitor control). The bars represent the mean \pm s.d. of the representative data of at least three independent experiments.

autophagosomes, where it has a role in both membrane fusion and selection of cargo for degradation (Barth et al, 2010). Western blot analysis demonstrated that LC3B-II was induced by all four sigma2 ligands $(100 \mu \mathrm{M}$ WC-26, $100 \mu \mathrm{M}$ SV119, $40 \mu \mathrm{M}$ RHM-138 and $10 \mu \mathrm{M}$ siramesine) over a 24 -h period (Figure 5). We also tested whether the mTOR signalling pathway is involved in sigma-2 ligand-induced autophagy. Western blot analysis showed that phosphorylation of p70S60 kinase and 4EBP-1, both of which are downstream effectors of $\mathrm{mTORC1}$, were decreased by all four sigma-2 ligands, suggesting that the mTOR pathway is inhibited by sigma-2 ligands, which may in turn trigger autophagy (Figure 5).

\section{Sigma-2 ligands impaired the cell cycle in MDA-MB-435} cells

Deregulation of cell-cycle progression may cause cell death (Allan and Clarke, 2008; Clarke and Allan, 2009). Therefore, we examined the effects of sigma-2 ligands on the expression levels of all four major classes of cyclins (cyclin D1, E2, A and B1) and on the phosphorylation levels of $\mathrm{Rb}$ by western blot analysis. MDA-MB435 cells were treated with $100 \mu \mathrm{M}$ WC-26, $100 \mu \mathrm{M}$ SV119, $40 \mu \mathrm{M}$ RHM-138 or $10 \mu \mathrm{M}$ siramesine for $0,1,2,4,8,16$ and $24 \mathrm{~h}$. The data showed that all four sigma-2 ligands decreased the expression levels of cyclin D1 in a time-dependent manner (Figure 6). In addition, the data showed that $100 \mu \mathrm{M}$ WC-26 or $100 \mu \mathrm{M} \mathrm{SV} 119$ mainly decreased cyclin B1, E2 and phospho-Rb (pRb); $40 \mu \mathrm{M}$ RHM-138 mainly decreased cyclin E2; and $10 \mu \mathrm{M}$ siramesine mainly decreased cyclin B1 and pRb. It is well known that $D$-type cyclins are responsible for progression through $G_{1}$ phase; E-type cyclins for completion of $G_{1}$ phase and entry into $S$-phase; A-type cyclins for driving the transition from S-phase to M-phase $\left(G_{2}\right.$ phase); and B-type cyclins for cell progression through M-phase (Malumbres and Barbacid, 2009). Our data suggest that all four sigma-2 ligands may block $G_{1}$-phase progression by decreasing cyclin D1 expression. In addition, WC-26 and SV119 may block cell entry from $\mathrm{G}_{1}$ to $\mathrm{S}$-phase by decreasing cyclin E2, and block mitosis by decreasing cyclin B1; RHM-138 may block cell entry from $G_{1}$ to $S$ phase by decreasing cyclin $E 2$; and siramesine may block mitosis by decreasing cyclin B1. Collectively, our data suggest that all four sigma-2 ligands may impair the cell cycle in multiple phases $\left(G_{1}, S, G_{2}\right.$ and $\left.M\right)$, which may lead to apoptosis either directly or indirectly, as discussed below.

\section{DISCUSSION}

We studied the cell death mechanisms of three sigma- 2 receptor ligands developed in our group and compared the results with the known sigma-2 agonist, siramesine. All four sigma-2 ligands induced cell death in EMT- 6 and MDA-MB-435 cells. Our results indicated that (1) the apoptotic pathway is, in part, responsible for cell death; (2) the sigma-2 ligands induced autophagy; and (3) the sigma-2 ligands impaired cell-cycle progression.

We first examined whether the sigma-2 ligands induced cell death through activating apoptosis. All three ligands induced Annexin-V-positive cells (Supplementary Figure 1), DNA fragmentation, caspase- 3 activation and PARP-1 cleavage. In addition, at least one sigma-2 ligand, RHM-138, activated caspase- 8 and 9 (Supplementary Figure 2). These results suggest that sigma-2 ligands induced apoptosis possibly through both intrinsic and extrinsic pathways. This conclusion is consistent with that reported from other laboratories (Crawford and Bowen, 2002; Ostenfeld et al, 2005). Our data also showed that the broadspectrum caspase inhibitor, Z-VAD-FMK, partially inhibited DNA fragmentation and cytotoxicity of the sigma-2 ligands, suggesting that caspases are, in part, responsible for sigma-2 ligand (WC-26, SV119 and RHM-138)-induced cell death in EMT-6 and MDA-MB435 cells. In previous studies, Crawford et al showed that the caspase inhibitors had no effect on sigma-2 ligand (CB-64D and CB-184) cytotoxicity or Annexin- $\mathrm{V}$ binding in human breast MCF-7 cells (Crawford and Bowen, 2002). Ostenfeld et al (2005) reported that caspase inhibitors failed to protect cells against siramesine-induced death in murine fibrosarcoma cells (WEHI-S) and MCF-7 cells. It appears that whether caspases are involved in sigma-2-induced cell death depends on the structure of the ligand, ligand concentration and tumour cell type. 

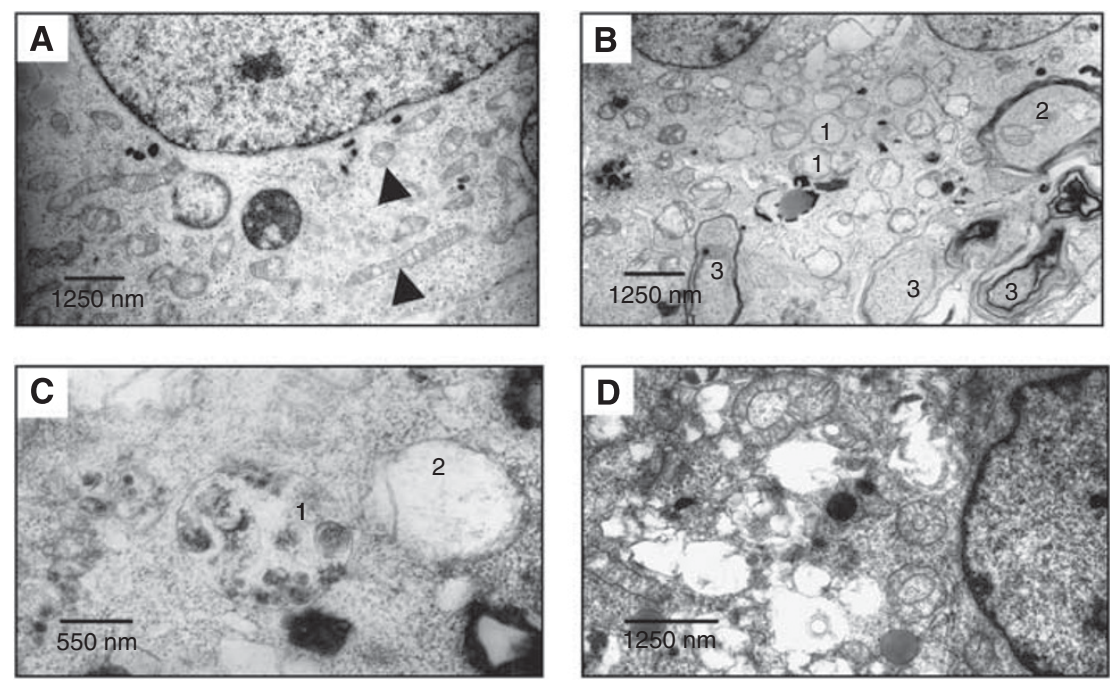

Figure 4 WC-26 and siramesine induced the formation of autophagosomes in MDA-MB-435 cells studied by transmission electron microscopy. (A) Cells without any treatment showed normal mitochondria ultrastructure (arrows). (B) Treatment with $100 \mu \mathrm{M}$ WC-26 for $4 \mathrm{~h}$ induced mitochondrial swelling (indicated by I), multilayer membrane compartments containing mitochondria and other cytoplasm contents (indicated by 2), and various kinds of multilayer

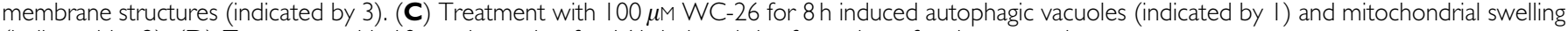
(indicated by 2). (D) Treatment with $10 \mu \mathrm{M}$ siramesine for $16 \mathrm{~h}$ induced the formation of various vacuoles.
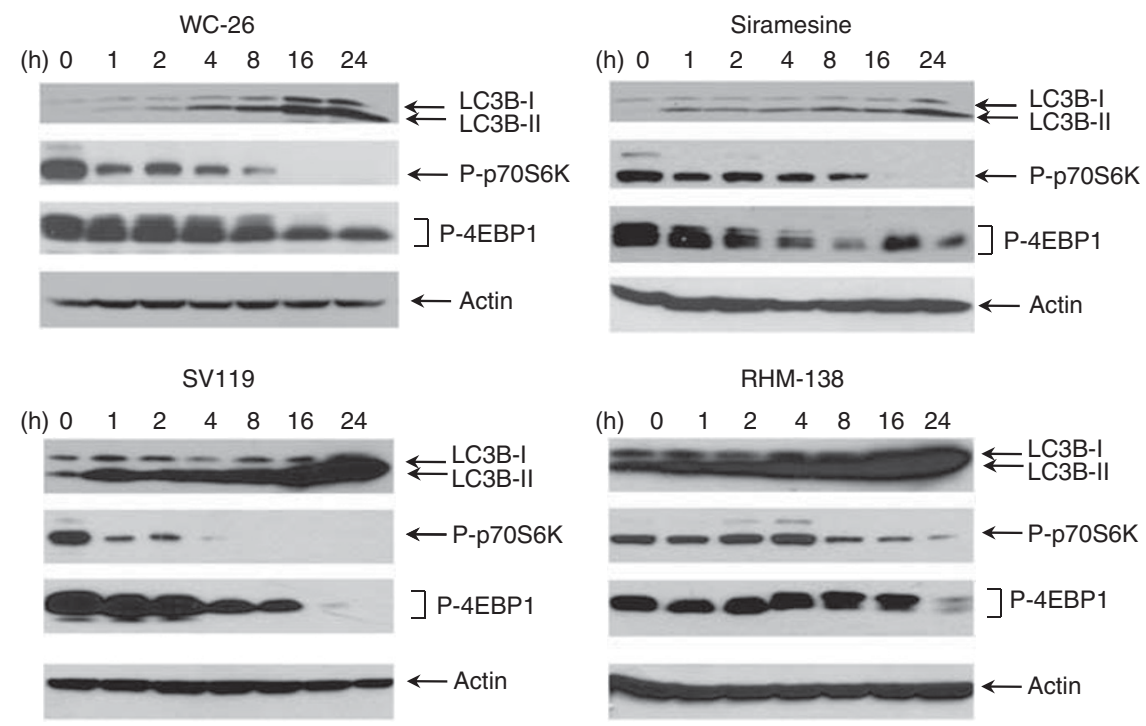

Figure 5 Sigma-2 ligands induced autophagy in MDA-MB-435 cells. Cells were treated with WC-26 (I00 $\mu \mathrm{M})$, SVI I9 (I00 $\mu \mathrm{M})$, RHM- I38 (40 $\mu \mathrm{M})$ or siramesine $(10 \mu \mathrm{M})$ for $0-24 \mathrm{~h}$. Autophagosome markers, LC3B and the downstream effectors of mTOR, p70S6K and 4EBPI, were analysed by western blotting.

We examined whether sigma-2 ligands induced autophagy. Electron microscopic data showed that the sigma-2 ligands WC-26 and siramesine induced mitochondrial swelling and formation of multilayer membrane vacuoles (Figure $4 \mathrm{~A}-\mathrm{D}$ ). The sigma-2 ligands also increased the expression of the autophagosome marker LC3B, and decreased the downstream effectors of mTOR, p70S6K and 4EBP1 (Figure 5). These results suggest that sigma-2 ligands induce autophagy most likely by inhibiting the mTOR pathway. These data are consistent with the previous report that siramesine induced autophagosome formation in MCF-7 cells (Ostenfeld et al, 2008). Autophagy has a dual role in cell survival and cell death. On one hand, autophagy is generally thought of as a survival mechanism through removal misfolded proteins and damaged organelles. On the other hand, excess levels of autophagy may lead to cell death (Platini et al, 2010). Ostenfeld et al (2008) showed that 3-methyladenine, an autophagy inhibitor, increased cytotoxicity induced by siramesine. They also showed that inhibition of autophagy by RNA interference-based depletion of the autophagy protein beclin 1 increased cell toxicity of siramesine. These data suggest that siramesine-induced autophagy is cytoprotective in MCF-7 cells and NIH3T3 cells. Studies of a variety of experimental systems indicate that whether autophagy is cytoprotective or cytotoxic is likely to be context- and cell typedependent (Platini et al, 2010). The role of our sigma-2 ligands, WC-26, SV119 and RHM-138, in autophagy in MDA-MB-435 cells needs to be further studied.

In the current work, we studied the effects of sigma-2 ligands on cell-cycle progression by examining the protein levels of the four major classes of cyclins. Our data showed that sigma-2 ligands altered cyclin protein expression levels and the phosphorylation 
WC-26
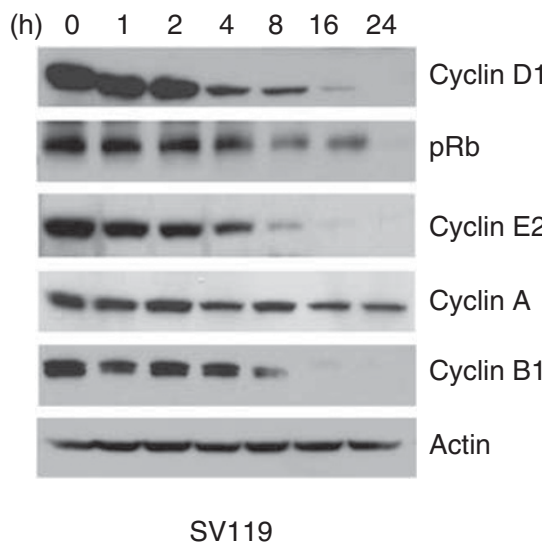

(h) $\begin{array}{lllllll}0 & 1 & 2 & 4 & 8 & 16 & 24\end{array}$

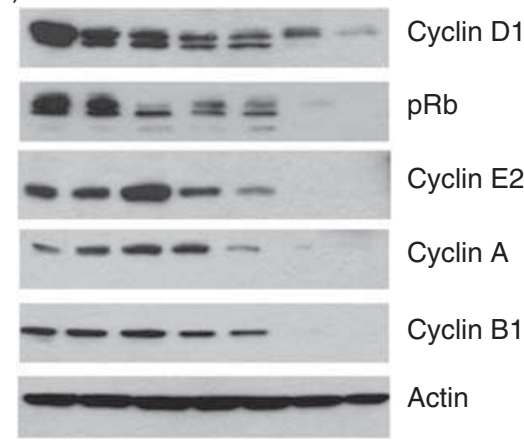

Siramesine

(h) $\begin{array}{lllllll}0 & 1 & 2 & 4 & 8 & 16 & 24\end{array}$

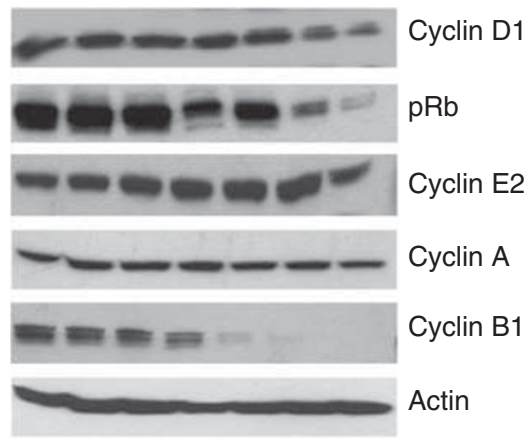

RHM-138

(h) $\begin{array}{lllllll}0 & 1 & 2 & 4 & 8 & 16 & 24\end{array}$

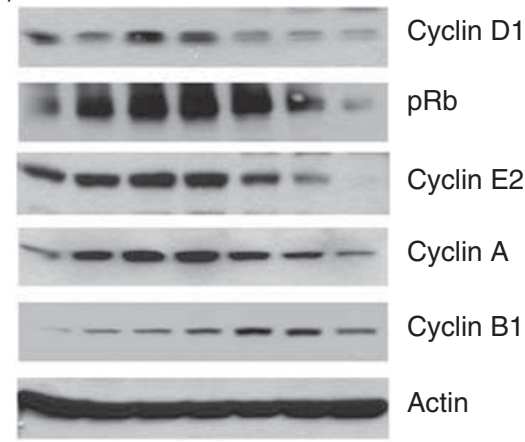

Figure 6 Sigma-2 ligands impaired cell-cycle progression in MDA-MB-435 cells. Cells were treated with WC-26 (I00 $\mu \mathrm{M})$, SV I I9 (I00 $\mu \mathrm{M})$, RHM- I 38 $(40 \mu \mathrm{M})$ or siramesine $(\mathrm{I} 0 \mu \mathrm{M})$ for $0-24 \mathrm{~h}$. The expression levels of cyclin DI, pRb, cyclin E2, cyclin A and cyclin BIwere analysed by western blotting.

levels of $\mathrm{Rb}$ (Figure 6). These data suggest that sigma-2 ligands may induce cell death by impairing cell-cycle progression. Regulation of cyclin levels has been extensively studied. Cyclin D1 protein is subject to transcriptional regulation and ubiquitinmediated proteolysis (Witzel et al, 2010). Unlike other cyclins, cyclin D1 is strongly dependent on extracellular mitogenic signals. For example, cyclin D1 is induced by the Ras-signalling pathway (Malumbres and Barbacid, 2001). It is possible that sigma-2 ligands decrease cyclin D1 by inhibiting the mitogenic signalling pathways or/and by increasing ubiquitin-dependent degradation processes. The $\mathrm{Rb}$ represses transcription by binding to transcription factors such as E2F-family members. D-type cyclins in complexes with CDK4 and/or CDK6 result in phosphorylation of $\mathrm{Rb}$ (Malumbres and Barbacid, 2005). This liberates E2F transcription factors and promotes the subsequent transcription of many important proteins such as cyclin E. In the present study, we show that the phosphorylation levels of Rb are decreased by WC-26, SV119 and siramesine. This could result from cyclin D1 reduction upon treatment with these ligands. The E-type cyclins are regulated transcriptionally by the phosphorylation status of $\mathrm{Rb}$ as well as by ubiquitin-dependent degradation mechanisms (Musgrove, 2006; Caldon and Musgrove, 2010). Our data show that WC-26 and SV119 decrease cyclin E2. This is probably due to reduction of phospho- $\mathrm{Rb}$. By contrast, siramesine does not reduce cyclin E2. One possible reason is that siramesine decreases cyclin $\mathrm{E} 2$ by reducing phospho- $\mathrm{Rb}$, but at the same time increases cyclin E2 by inhibiting its degradation. The net result is no change of cyclin E2 expression. A- and B-type cyclins are also regulated at the transcriptional level and by ubiquitin-mediated proteolysis (Miyazaki and Arai, 2007). The current study shows that WC-26, SV119 and siramesine caused a dramatic decrease in cyclin B1 expression. This could result from decreasing the transcription and/or increasing the ubiquitin-dependent degradation processes.
Taking these data together, the sigma-2 ligands decrease multiple cyclin protein levels. Decreasing cyclin levels has been proposed as a therapeutic strategy for cancer treatment (Freemantle et al, 2007). Our findings suggest that the sigma-2 ligands may serve as promising antitumour drugs by disrupting cell-cycle progression.

Sigma-2 ligands induce apoptosis, autophagy and cell-cycle impairment. These pathways are inter-related. Autophagy and cellcycle arrest are known adaptive responses of cells to toxic insults (Clarke and Allan, 2009; Wyllie, 2010). Cells can remove the misfolded proteins and damaged organelles by autophagy. Cells can also activate cell-cycle checkpoints, which provide an opportunity to repair the damage. It is possible that upon sigma2 ligand treatment, cells initiate autophagy and cell-cycle arrest to protect themselves from the toxic effects of the ligands. After these mechanisms fail to rescue the cells, they switch to facilitate cell death. Understanding the turning points where adaptive responses become contributors to toxicity is important for designing effective cancer therapeutic interventions. The PI3K/Akt/mTOR pathway is well known as one of the key molecular switches between apoptosis and autophagy (Moretti et al, 2007; Wyllie, 2010; Li et al, 2011). Our data suggest that sigma-2 ligands increase autophagy and apoptosis by suppressing the mTOR pathway. In addition, recent studies have revealed that the cell-cycle components can be directly involved in apoptosis. It is reported that CDK1 - cyclin B1 is a crucial regulator of not only mitosis but also apoptosis (Clarke and Allan, 2009). Cyclin-dependent kinase$1-$ cyclin B1 phosphorylates the inhibitory site on caspase-9 (Thr125) during mitosis (Allan and Clarke, 2007). Phosphorylation of this site restrains caspase-9 activation and apoptosis. It is possible that the decrease in cyclin B1 upon treatment of the sigma-2 ligands reduces the phosphorylation level of caspase- 9 at the inhibitory site and thus activates caspase- 9 and apoptosis. 
Previously we have shown that the sigma-2 fluorescent ligands rapidly internalise into cells and localise in the mitochondria, lysosomes, endoplasmic reticulum and plasma membranes (Zeng et al, 2007, 2011). It is possible that sigma-2 ligands trigger multiple signalling pathways by binding to sigma-2 receptors located in multiple cytoplasmic organelles and plasma membranes For example, sigma-2 ligands may bind to mitochondria and damage their structure and function, as shown by mitochondrial swelling (Figure 4B and C), and trigger caspase-3-dependent or independent apoptosis (Crawford and Bowen, 2002; Ostenfeld et al, 2005). Sigma-2 ligands may bind to lysosomes, and cause lysosomal leakage and cell death as demonstrated previously by Ostenfeld et al (2005). The damage to cytoplasmic organelles by sigma-2 ligands may trigger autophagy, which may have either a survival or a detrimental role depending on the structure of the drugs and the tumour cell type.

Positron emission tomography imaging in rodent (Mach et al, 2001a; Kawamura et al, 2003) and human studies (unpublished data) has demonstrated that sigma-2 ligands selectively target tumours in vivo. Sigma-2 receptor ligands have shown efficacy in various tumour cells using cell culture and animal models (Ostenfeld et al, 2005; Kashiwagi et al, 2007, 2009) by multiple signalling pathways. These characteristics make sigma-2 ligands promising chemotherapeutic drugs for treating a variety of tumours.

\section{ACKNOWLEDGEMENTS}

We thank Marilyn Levy in the Cell Biology and Physiology Electron Microscopy Facility for assistance. We also thank our colleague Lynne A Jones for outstanding editorial assistance. This work was supported by grant CA102869 awarded by the National Cancer Institute and GM 44118 by the National Institute of General Medical Sciences.

Supplementary Information accompanies the paper on British Journal of Cancer website (http://www.nature.com/bjc)

\section{REFERENCES}

Allan LA, Clarke PR (2007) Phosphorylation of caspase-9 by CDK1/cyclin B1 protects mitotic cells against apoptosis. Mol Cell 26: $301-310$

Allan LA, Clarke PR (2008) A mechanism coupling cell division and the control of apoptosis. SEB Exp Biol Ser 59: 257-265

Barbieri F, Sparatore A, Alama A, Novelli F, Bruzzo C, Sparatore F (2003) Novel sigma binding site ligands as inhibitors of cell proliferation in breast cancer. Oncol Res 13: $455-461$

Barth S, Glick D, Macleod KF (2010) Autophagy: assays and artifacts. J Pathol 221: $117-124$

Bem WT, Thomas GE, Mamone JY, Homan SM, Levy BK, Johnson FE, Coscia CJ (1991) Overexpression of sigma receptors in nonneural human tumors. Cancer Res 51: 6558-6562

Brent PJ, Pang G, Little G, Dosen PJ, Van Helden DF (1996) The sigma receptor ligand, reduced haloperidol, induces apoptosis and increases intracellular-free calcium levels $[\mathrm{Ca} 2+] \mathrm{i}$ in colon and mammary adenocarcinoma cells. Biochem Biophys Res Commun 219: $219-226$

Caldon CE, Musgrove EA (2010) Distinct and redundant functions of cyclin E1 and cyclin E2 in development and cancer. Cell Div 5: 2

Cassano G, Gasparre G, Niso M, Contino M, Scalera V, Colabufo NA (2009) F281, synthetic agonist of the sigma-2 receptor, induces $\mathrm{Ca} 2+$ efflux from the endoplasmic reticulum and mitochondria in SK-N-SH cells. Cell Calcium 45: $340-345$

Caveliers V, Everaert H, Lahoutte T, Dierickx LO, John CS, Bossuyt A (2001) Labelled sigma receptor ligands: can their role in neurology and oncology be extended? Eur J Nucl Med 28: 133-135

Clarke PR, Allan LA (2009) Cell-cycle control in the face of damage - a matter of life or death. Trends Cell Biol 19: 89-98

Colabufo NA, Berardi F, Contino M, Ferorelli S, Niso M, Perrone R, Pagliarulo A, Saponaro P, Pagliarulo V (2006) Correlation between sigma2 receptor protein expression and histopathologic grade in human bladder cancer. Cancer Lett 237: $83-88$

Crawford KW, Bittman R, Chun J, Byun HS, Bowen WD (2003) Novel ceramide analogues display selective cytotoxicity in drug-resistant breast tumor cell lines compared to normal breast epithelial cells. Cell Mol Biol (Noisy-le-grand) 49: 1017 - 1023

Crawford KW, Bowen WD (2002) Sigma-2 receptor agonists activate a novel apoptotic pathway and potentiate antineoplastic drugs in breast tumor cell lines. Cancer Res 62: 313-322

Crawford KW, Coop A, Bowen WD (2002) Sigma(2) receptors regulate changes in sphingolipid levels in breast tumor cells. Eur J Pharmacol 443: 207-209

Freemantle SJ, Liu X, Feng Q, Galimberti F, Blumen S, Sekula D, Kitareewan S, Dragnev KH, Dmitrovsky E (2007) Cyclin degradation for cancer therapy and chemoprevention. J Cell Biochem 102: 869-877

Glick D, Barth S, Macleod KF (2010) Autophagy: cellular and molecular mechanisms. J Pathol 221: 3-12
Hanner M, Moebius FF, Flandorfer A, Knaus HG, Striessnig J, Kempner E, Glossmann H (1996) Purification, molecular cloning, and expression of the mammalian sigmal-binding site. Proc Natl Acad Sci USA 93: 8072-8077

Hellewell SB, Bruce A, Feinstein G, Orringer J, Williams W, Bowen WD (1994) Rat liver and kidney contain high densities of sigma 1 and sigma 2 receptors: characterization by ligand binding and photoaffinity labeling. Eur J Pharmacol 268: 9-18

Jacobson MD, Weil M, Raff MC (1997) Programmed cell death in animal development. Cell 88: 347 - 354

Janku F, McConkey DJ, Hong DS, Kurzrock R (2011) Autophagy as a target for anticancer therapy. Nat Rev Clin Oncol 8: 528-539

John CS, Gulden ME, Li J, Bowen WD, McAfee JG, Thakur ML (1998) Synthesis, in vitro binding, and tissue distribution of radioiodinated 2-[125I]N-(N-benzylpiperidin-4-yl)-2-iodo benzamide, 2-[125I]BP: a potential sigma receptor marker for human prostate tumors. $\mathrm{Nucl} \mathrm{Med}$ Biol 25: $189-194$

Kashiwagi H, McDunn JE, Simon Jr PO, Goedegebuure PS, Vangveravong S, Chang K, Hotchkiss RS, Mach RH, Hawkins WG (2009) Sigma-2 receptor ligands potentiate conventional chemotherapies and improve survival in models of pancreatic adenocarcinoma. J Transl Med 7: 24

Kashiwagi H, McDunn JE, Simon Jr PO, Goedegebuure PS, Xu J, Jones L, Chang K, Johnston F, Trinkaus K, Hotchkiss RS, Mach RH, Hawkins WG (2007) Selective sigma-2 ligands preferentially bind to pancreatic adenocarcinomas: applications in diagnostic imaging and therapy. Mol Cancer 6: 48

Kawamura K, Elsinga PH, Kobayashi T, Ishii S, Wang WF, Matsuno K, Vaalburg W, Ishiwata K (2003) Synthesis and evaluation of $11 \mathrm{C}$ - and 18F-labeled 1-[2-(4-alkoxy-3-methoxyphenyl)ethyl]-4-(3-phenylpropyl)piperazines as sigma receptor ligands for positron emission tomography studies. Nucl Med Biol 30: 273-284

Li CY, Wang EQ, Cheng Y, Bao JK (2011) Oridonin: an active diterpenoid targeting cell cycle arrest, apoptotic and autophagic pathways for cancer therapeutics. Int J Biochem Cell Biol 43: 701 - 704

Mach RH, Huang Y, Buchheimer N, Kuhner R, Wu L, Morton TE, Wang L, Ehrenkaufer RL, Wallen CA, Wheeler KT (2001a) [(18)F] $N$-(4'-fluorobenzyl)-4-(3-bromophenyl) acetamide for imaging the sigma receptor status of tumors: comparison with [(18)F]FDG, and [(125)I]IUDR. Nucl Med Biol 28: $451-458$

Mach RH, Huang Y, Freeman RA, Wu L, Vangveravong S, Luedtke RR (2004) Conformationally-flexible benzamide analogues as dopamine D3 and sigma 2 receptor ligands. Bioorg Med Chem Lett 14: 195-202

Mach RH, Smith CR, al-Nabulsi I, Whirrett BR, Childers SR, Wheeler KT (1997) Sigma 2 receptors as potential biomarkers of proliferation in breast cancer. Cancer Res 57: $156-161$

Mach RH, Vangveravong S, Huang Y, Yang B, Blair JB, Wu L (2003) Synthesis of $\mathrm{N}$-substituted 9-azabicyclo[3.3.1]nonan-3a-yl phenylcarbamate analogs as sigma-2 receptor ligands. Med Chem Res 11: 380-398 
Mach RH, Yang B, Wu L, Kuhner R, Whirrett B, West T (2001b) Synthesis and sigma receptor binding affinities of 8-azabicyclo[3.2.1]octan-3a-yl and 9-azabicyclo[3.3.1]nonan-3a-yl phenyl carbamates. Med Chem Res 10: $339-355$

Malumbres M, Barbacid M (2001) To cycle or not to cycle: a critical decision in cancer. Nat Rev Cancer 1: 222-231

Malumbres M, Barbacid M (2005) Mammalian cyclin-dependent kinases. Trends Biochem Sci 30: 630-641

Malumbres M, Barbacid M (2009) Cell cycle, CDKs and cancer: a changing paradigm. Nat Rev Cancer 9: $153-166$

Megalizzi V, Le Mercier M, Decaestecker C (2010) Sigma receptors and their ligands in cancer biology: overview and new perspectives for cancer therapy. Med Res Rev; e-pub ahead of print 4 August 2010; doi:10.1002/med.20218

Miyazaki T, Arai S (2007) Two distinct controls of mitotic cdk1/cyclin B1 activity requisite for cell growth prior to cell division. Cell Cycle 6: $1419-1425$

Moretti L, Cha YI, Niermann KJ, Lu B (2007) Switch between apoptosis and autophagy: radiation-induced endoplasmic reticulum stress? Cell Cycle 6: $793-798$

Musgrove EA (2006) Cyclins: roles in mitogenic signaling and oncogenic transformation. Growth Factors 24: 13 - 19

Ostenfeld MS, Fehrenbacher N, Hoyer-Hansen M, Thomsen C, Farkas T, Jaattela M (2005) Effective tumor cell death by sigma-2 receptor ligand siramesine involves lysosomal leakage and oxidative stress. Cancer Res 65: $8975-8983$

Ostenfeld MS, Hoyer-Hansen M, Bastholm L, Fehrenbacher N, Olsen OD, Groth-Pedersen L, Puustinen P, Kirkegaard-Sorensen T, Nylandsted J, Farkas T, Jaattela M (2008) Anticancer agent siramesine is a lysosomotropic detergent that induces cytoprotective autophagosome accumulation. Autophagy 4: 487-499

Platini F, Perez-Tomas R, Ambrosio S, Tessitore L (2010) Understanding autophagy in cell death control. Curr Pharm Des 16: 101-113

Reed JC (2002) Apoptosis-based therapies. Nat Rev Drug Discov 1: 111 - 121
Roperto S, Colabufo NA, Inglese C, Urraro C, Brun R, Mezza E, Staibano S, Raso C, Maiolino P, Russo V, Palma E, Roperto F (2010) Sigma-2 receptor expression in bovine papillomavirus-associated urinary bladder tumours. J Comp Pathol 142: 19-26

Seth P, Leibach FH, Ganapathy V (1997) Cloning and structural analysis of the cDNA and the gene encoding the murine type 1 sigma receptor. Biochem Biophys Res Commun 241: 535-540

Vilner BJ, John CS, Bowen WD (1995) Sigma-1 and sigma-2 receptors are expressed in a wide variety of human and rodent tumor cell lines. Cancer Res 55: $408-413$

Walker JM, Bowen WD, Walker FO, Matsumoto RR, De Costa B, Rice KC (1990) Sigma receptors: biology and function. Pharmacol Rev 42: $355-402$

Wheeler KT, Wang LM, Wallen CA, Childers SR, Cline JM, Keng PC, Mach RH (2000) Sigma-2 receptors as a biomarker of proliferation in solid tumours. Br J Cancer 82: $1223-1232$

Witzel II, Koh LF, Perkins ND (2010) Regulation of cyclin D1 gene expression. Biochem Soc Trans 38: $217-222$

Wyllie AH (2010) 'Where, O death, is thy sting?' A brief review of apoptosis biology. Mol Neurobiol 42: 4-9

Xu J, Zeng C, Chu W, Pan F, Rothfuss JM, Zhang F, Tu Z, Zhou D, Zeng D, Vangveravong S, Johnston F, Spitzer D, Chang KC, Hotchkiss RS, Hawkins WG, Wheeler KT, Mach RH (2011) Identification of the PGRMC1 protein complex as the putative sigma-2 receptor binding site. Nat Commun 2: 380

Zeng C, Vangveravong S, Jones LA, Hyrc K, Chang KC, Xu J, Rothfuss JM, Goldberg MP, Hotchkiss RS, Mach RH (2011) Characterization and evaluation of two novel fluorescent sigma-2 receptor ligands as proliferation probes. Mol Imaging 10: $420-433$

Zeng C, Vangveravong S, Xu J, Chang KC, Hotchkiss RS, Wheeler KT, Shen D, Zhuang ZP, Kung HF, Mach RH (2007) Subcellular localization of sigma-2 receptors in breast cancer cells using two-photon and confocal microscopy. Cancer Res 67: 6708-6716

This work is published under the standard license to publish agreement. After 12 months the work will become freely available and the license terms will switch to a Creative Commons Attribution-NonCommercial-Share Alike 3.0 Unported License. 